Experimental and numerical evaluation of the structural performance of Uruguayan Eucalyptus grandis fingerjoint

\title{
Experimental and numerical evaluation of the structural performance of Uruguayan Eucalyptus grandis finger-joint
}

\author{
Abel Vega ${ }^{1}$, Vanesa Baño ${ }^{1 *}$, Andrea Cardoso $^{2}$, Laura Moya ${ }^{3}$ \\ ${ }^{1}$ Instituto de Estructuras y \\ ${ }^{2}$ Laboratorio Tecnológico del \\ ${ }^{3}$ Facultad de Arquitectura \\ Transporte. Facultad de \\ Uruguay-LATU \\ Ingeniería. \\ Montevideo, 11500, Uruguay \\ Universidad ORT Uruguay \\ Montevideo, 11300, Uruguay \\ Universidad de la República.
}

Montevideo, 11300, Uruguay

\begin{abstract}
The aim of this study was to evaluate the structural performance of finger-joints made of Uruguayan Eucalyptus grandis and two types of adhesives. A numerical model for bending strength and stiffness prediction was developed. Model inputs were experimentally determined from tests on wooden specimens and from literature. Finger-joints glued with two types of adhesives (one-component polyurethane-PUR-and emulsion polymer isocyanate-EPI-) were tested in bending and the failure modes were evaluated. Results show that adhesive type did not influence the stiffness of the finger-joint, while did influence the bending strength. Specimens glued with PUR showed higher strength than those glued with EPI. A 3D model, using Comsol Multiphisic software, was developed to simulate the finger-joint behavior. Adhesive-wood interaction in the finger-joints was modeled using the Comsol Thin Elastic Layer module, defined by the elastic properties of the adhesives. The numerical results showed no differences on the stiffness of the joints regardless of adhesive type. Results agreed with those obtained from experimental tests, with a maximum error of $7 \%$. Models predicted the bending strength with an error of $6 \%$ with respect to the experimental values. Different finger configurations were analyzed, and the optimal geometry (20 mm-length, 6.2 mm-pitch and $1.0 \mathrm{~mm}$-tip-thick) to attain the maximum strength for Uruguayan Eucalyptus was found.
\end{abstract}

\section{INTRODUCTION}

Glued laminated timber (GLT or glulam) is one of the most important engineered wood products (EWP) used at present, in architecture and civil engineering. The manufacturing process is complex and involves many factors, such as species, adhesive type and applied pressure, among others. Optimum parameter combinations, both in glulam and lamella production, must be tailored to meet end-product's requirements. The efficiency of the longitudinal union of lamellas through suitable finger-joints is crucial for the overall structural performance of GLT and is close related to the manufacturing process. Production requirements, for GLT and finger-joint have been well documented, and for softwood species and poplar are established in EN 14080 (CEN 2013). However, there are still several unknowns regarding finger jointing for hardwoods, or for new species/adhesives combinations. The influence of the manufacturing process on the mechanical properties of finger-joint hardwoods has been approached with emphasis on the production conditions such as timber conditioning (Raknes 1980), curing time and end pressure (Bourreau et al. 2013), finger-joint geometry (Ahmad et al. 2017; Özçif̧̧i 2008; Ayarkwa et al. 2000) and other several interlinked factors (Vrazel 2004). In addition, an extensive literature related to the gluing performance and adhesive evaluation is available (Ayarkwa et al. 2000; Vassiliou et al. 2006; Volkmer et al. 2014).

The principal criterion for structural finger-joint assessment is the load bearing strength, usually evaluated by static bending test. The test is considered as the most convenient for a preliminary study of finger joints and is commonly employed for quality control as well. Frequently, experimental programs are complemented with numerical simulations with the aim of modelling the mechanical behavior of finger joints. Finite element method (FEM) has been used for simulation in analyses of wooden materials for over 30 years, due to the ability for dealing with the structural complexity of wood (Sebera et al. 2015), and has been reported as a convenient approach to model wooden materials when limited experimental data is available (Tran et al. 2014). Several researchers have successfully applied FEM to simulate the stress distribution in finger joints of softwood (HR and E 1991; Serrano et al. 2001; Khelifa et al. 2015) and hardwood species (Smardzewski 1996; Tran et al. 2014; Franke and Marto 2014).

The main difficulty of finger-jointing hardwoods lies in the uncertainties of the wood-adhesive interaction. In particular, some species of Eucalyptus are not fully characterized, and therefore their interaction with some adhesives 
is still unknown. Such is the case of Uruguayan fast growing Eucalytpus spp., one of the most important renewable genres cultivated in Uruguay that covers more than 600,000 ha and annually produce approximately $11.2 \mathrm{million}$ m 3 of roundwood. The major part is consumed by pulp and energy production, and 1.2 million m3 from the annual average supply is intended for mechanical transformation (Dieste 2012). Having growth rates of 30m3ha-1yr-1, Eucalyptus grandis is a promising raw material for GLT production in Uruguay. Information on suitable adhesives for finger-jointing Eucalyptus grandis is scarce. The most commonly adhesive used for Eucalyptus glulam are phenoplast or aminosplast adhesives (Piter et al. 2007a). However, in the last years, one-component polyurethane (PUR) and emulsion polymer isocyanate (EPI) adhesives are gaining acceptance for structural applications, and recently, they have been included in the European standards EN 14080 (CEN 2013) and EN 16351 (CEN 2015). Recently, few studies on glulam made of Eucalyptus globulus (Lara-Bocanegra et al. 2017; Franke and Marto 2014), Eucalyptus grandis (Moya et al. 2019; Bourscheid et al. 2015; Calil Neto et al. 2014) and a hybrid of two Eucalyptus species (Pereira et al. 2016), showed the potential of PUR with this genus. In general, the mechanical properties of glulam achieved values above those of the corresponding solid wood; however certain difficulties related to the integrity of the glue line were also reported in these works. Literature on glulam made of hardwoods and EPI is limited; few works report on tropical species such as teak (Iwakiri et al. 2014), and beech (Volkmer et al. 2014). A study by Franke et al. (Franke et al. 2014) comparing the finger joint performance of beech and PUR or beech and EPI, revealed no substantial difference in strength results. In general, the mechanical properties of glulam achieved values above those of the corresponding solid wood; however certain difficulties related to the integrity of the glue line were also reported in these works. Literature on glulam made of hardwoods and EPI is limited; few works report on tropical species such as teak (Iwakiri et al. 2014), and beech (Volkmer et al. 2014). A study by Franke et al. (Franke et al. 2014) comparing the finger joint performance of beech and PUR or beech and EPI, revealed no substantial difference in strength results.

Knowing the influence of the gluing quality on the successful performance of the finger-joint, several works have focused on analyzing the adhesive-wood connection by models that simulate its behavior (Franke et al. 2014; Tran et al. 2014; Camú and Aicher 2018).

This study aims to evaluate the mechanical performance of finger-joints made of Eucalyptus grandis and two different adhesives, EPI and PUR, focusing on the bending properties and the glue line behavior. In addition, a numerical model to predict the modulus of elasticity and the bending strength of the finger-joints is presented.

\section{MATERIALS AND METHODS}

The study is divided in two phases: i) an empirical testing program on physical sections cut from lamellas, subjected to bending, and ii) numerical modeling of the finger-jointed sections using input data from phase i) tests.

\subsection{SAMPLING}

The material used in this study came from Eucalyptus grandis sawn boards that have been previously graded as Class 1 (IRAM 9662-2 2015), with corresponding values of $30 \mathrm{~N} / \mathrm{mm}^{2}$ for bending strength ( $\left.\mathrm{f}_{\mathrm{mk}}\right), 18 \mathrm{~N} / \mathrm{mm} 2 \mathrm{for}$ tension parallel to grain strength $\left(\mathrm{f}_{\mathrm{t}, 0, \mathrm{k}}\right), 14.000 \mathrm{~N} / \mathrm{mm}^{2}$ for longitudinal modulus of elasticity $\left(\mathrm{E}_{0, \text { mean }}\right)$, and $430 \mathrm{Kg} / \mathrm{m}^{3}$ for density $\left(\rho^{\mathrm{k}}\right)$.

A total of 80 specimens with nominal cross section of $70 \mathrm{~mm}$ x $22 \mathrm{~mm}$, and $400 \mathrm{~mm}$ long, were prepared from the selected boards, and divided in three groups: i) 40 with one finger-joint in the mid-span bonded with EPI; ii) 20 with one finger-joint bonded with PUR; and iii) 20 control (without finger-joint). The last group was prepared to determine input values for the FE modelling, and to compare the effect of the finger-joint with different adhesives, on the structural behavior of tested specimens.

All specimens were conditioned at $20^{\circ} \mathrm{C} / 65 \% \mathrm{RH}$ until they reach $12 \%$ moisture content. Finger-joints were then manufactured following the production requirements described on EN 14080 (CEN 2013), with manual application of the adhesive and with a finger profile as shown in Figure 1. 
Experimental and numerical evaluation of the structural performance of Uruguayan Eucalyptus grandis finger-joint
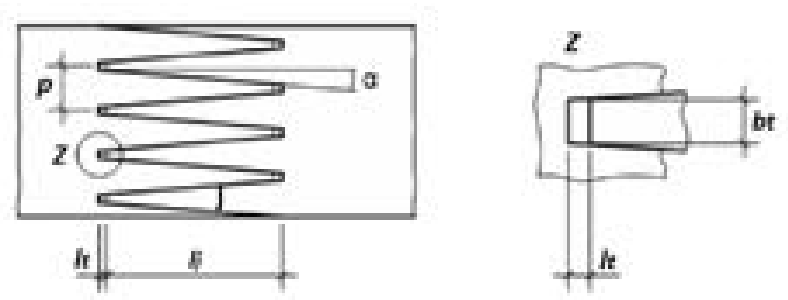

\begin{tabular}{llc}
\hline$l_{j}$ & Finger length & $15 \mathrm{~mm}$ \\
\hline$p$ & Pitch & $4 \mathrm{~mm}$ \\
\hline$l_{t}$ & Tip gap & $0,1 \mathrm{~mm}$ \\
\hline$b_{t}$ & Tip thickness & $0,5 \mathrm{~mm}$ \\
\hline
\end{tabular}

Figure 1: Finger-joint parameters (CEN 2013)

\subsection{TESTING}

The specimens were tested in flatwise bending following the recommendations of EN 14080 (CEN 2013) and EN 408 (CEN 2010). Modulus of elasticity and bending strength were calculated by Equations 1 and 2.

$$
\begin{aligned}
& E_{m}=\frac{3 a l^{2}-4 a^{3}}{2 b h^{3}\left(2 \frac{w_{2}-w_{1}}{F_{2}-F_{1}}\right)} \\
& f_{m}=\frac{3 F a}{b h^{2}}
\end{aligned}
$$

where

$\mathrm{h}$ and $\mathrm{b}$, are the height and width of the specimen, respectively, in $\mathrm{mm}$

$\mathrm{a}$, is the distance between one support and the nearest loading point (6h), in $\mathrm{mm}$

1 , is the span (18h), in $\mathrm{mm}$

$F_{1}-F_{2}$, is an increment of the load on the straight-line portion of the load deformation curve, in $\mathrm{kN}$

$\mathrm{w}_{1}-\mathrm{w}_{2}$, is the increment of deformation corresponding to $\mathrm{F}_{2}-\mathrm{F}_{1}$, in $\mathrm{mm}$

$\mathrm{F}$ is the maximum load at the failure, in $\mathrm{kN}$

In addition, the failure mode of the finger joints was visually evaluated and roughly assigned to one of the following types: i) mode 1, fracture occurs $100 \%$ by wood; ii) mode 2 , fracture partially occurs by wood and partially by adhesive; and iii) mode 3 , failure occurs $100 \%$ by adhesive. Figure 2 shows an example of each failure mode.

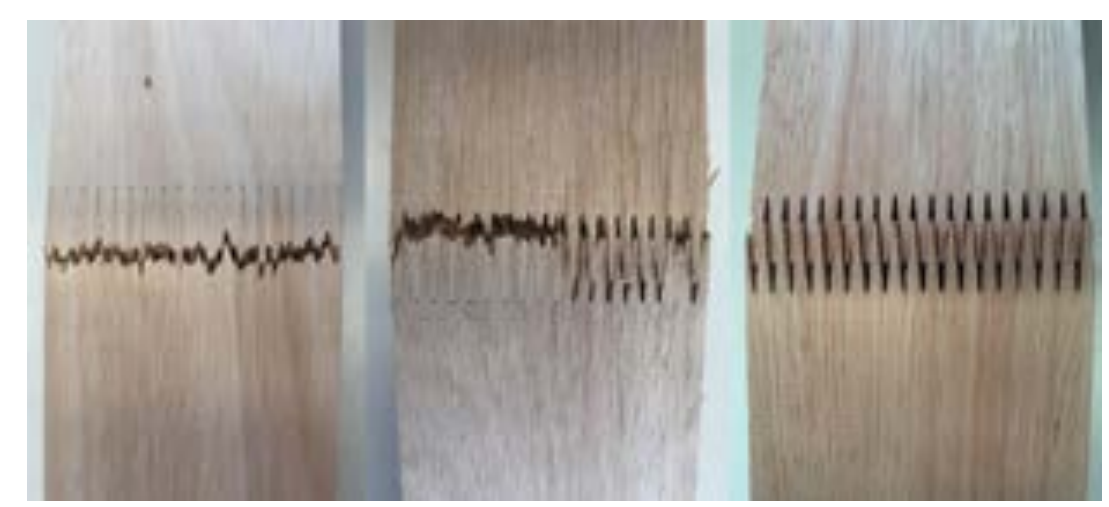

Figure 2: Failure modes of finger-joint lamellas: Mode 1 (left), Mode 2 (center) and Mode 3 (right)

\subsection{FE MODELING}

A 3D model, using Comsol Multiphysics software (Comsol Inc., USA), was developed to simulate the finger joint behavior of the lamellas in bending tests depending on the adhesive type. Variable mesh size, with a gradient ranging from 30 to $3 \mathrm{~mm}$ (decreasing close to the finger-joint proximities) at a maximum growth rate of 1.45, was employed (Figure 3). Typical 4-point bending test following EN 408 specifications (CEN 2010) was simulated using geometrical models of lamellas with dimensions of $70 \mathrm{~mm}$ - width, $22 \mathrm{~mm}$-depth, and $396 \mathrm{~mm}$-length. The applied loads were located on the central third and separated at a distance of $132 \mathrm{~mm}$. 


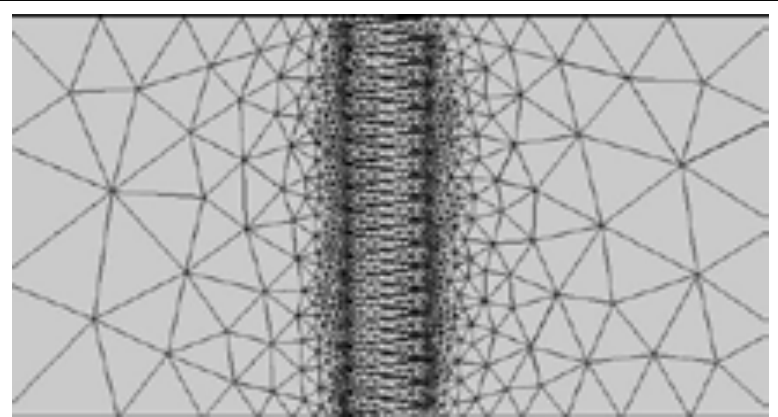

Figure 3: Meshing of sample on the Finite Element model

Timber was considered as an orthotropic and non-lineal material, whose elasto-plastic behavior was modeled through the Comsol hardening function obtained from control tests. Input data of the physical and mechanical properties were obtained from the experimental tests on the control samples (see 3.1.), and other relevant properties derived from the empirical equations established in EN 384 (CEN 2016a) for deciduous species (Eqs. 3, 4, 5, 6, 7, 8 and 9).

$$
\begin{aligned}
& E_{90}=E_{0} / 15 \\
& G=E_{0} / 16 \\
& f_{t, 0}=0,6 \cdot f_{m} \\
& \mathrm{ft}_{, 90}=0.6 \\
& f_{c, 0}=5 \cdot\left(f_{m}\right)^{0,45} \\
& f_{c, 90}=0,015 \cdot \rho \\
& \mathrm{f}_{\mathrm{v}}=4
\end{aligned}
$$

where,

$\mathrm{E}_{90}$ is the modulus of elasticity perpendicular to the grain

$\mathrm{E}_{0}$ is the modulus of elasticity parallel to the grain, obtained from experimental bending tests

$\mathrm{G}$ is the shear modulus

$\mathrm{f}_{\mathrm{t}, 0}$ is the strength in tension parallel to the grain

$\mathrm{f}_{\mathrm{c}, 0}$ is the strength in compression parallel to the grain

$\mathrm{f}_{\mathrm{c}, 90}$ is the strength in compression perpendicular to the grain

$\mathrm{f}_{\mathrm{v}}$ is the shear strength

$\mathrm{f}_{\mathrm{m}}$ is the bending strength, obtained from experimental bending tests

Adhesive-wood interaction in the finger joints was modeled through the Comsol Thin Elastic Layer module, defined by the elastic properties of the adhesives, shown in Table 1. Young modulus and Poisson coefficients were taken from Stoeckel et al. (Stoeckel et al. 2013) and de Castro (de Castro San Román 2005), and Konnerth and Muller (Konnerth et al. 2007), respectively. Shear modulus was determined by Equation 10 (Konnerth et al. 2007).

$$
G=E_{a d} / 2 *\left(1+v_{a d}\right)
$$

where

$E_{a d}$ is the Young modulus of the adhesive 
Experimental and numerical evaluation of the structural performance of Uruguayan Eucalyptus grandis finger-joint

$v_{a d}$ is the Poisson coefficient of the adhesive

Table 1: Adhesive properties used in FE simulations

\begin{tabular}{c|c|c|c}
\cline { 2 - 4 } & Property/Adhsive type & PUR & EPI \\
\hline Young modulus $(\mathrm{GPa})$ & $E_{a d}$ & 0.50 & 3.50 \\
Poisson coefficient & $v_{a d}$ & 0.30 & 0.30 \\
Shear modulus $(\mathrm{GPa})$ & $G_{a d}$ & 0.19 & 1.35 \\
\hline
\end{tabular}

\section{RESULTS AND DISCUSSION}

\subsection{CONTROL SAMPLES}

Experimental data of bending properties and density $\left(E_{0}, f_{m}\right.$, and $\left.\rho\right)$, plus other derived mechanical properties (G, $\mathrm{f}_{\mathrm{t}, 0}, \mathrm{f}_{\mathrm{c}, 0}, \mathrm{f}_{\mathrm{c}, 90}$ and $\mathrm{f}_{\mathrm{v}}$ ) from control samples, are shown in Table 2. Control samples were used as input data for FE modeling to predict the load-deflection curve in the elastic phase, without influence of the finger joints or the adhesive type. Control sample also provided input data to define the hardening function used in Comsol for the elastoplastic phase.

Table 2: Wood properties used in FE simulations. Mean values

\begin{tabular}{c|c|c|c|c|c|c|c|c|c}
\hline $\mathbf{E}_{\mathbf{0}}{ }^{\mathbf{1}}$ & $\mathbf{f}_{\mathbf{m}} \mathbf{1}^{\mathbf{1}}$ & $\mathbf{\rho}^{\mathbf{1} \mathbf{2}}$ & $\mathbf{E} \mathbf{9 0}$ & $\mathbf{G}$ & $\mathbf{f}_{\mathbf{t}, \mathbf{0}}$ & $\mathbf{f}_{\mathbf{c}, \mathbf{0}}$ & $\mathbf{f}_{\mathbf{t}, \mathbf{9 0}}$ & $\mathbf{f}_{\mathbf{c}, \mathbf{9 0}}$ & $\mathbf{f}_{\mathbf{v}}$ \\
\hline 15363 & 91.9 & 556 & 1024 & 960 & 55.1 & 38.2 & 0.6 & 8.3 & 4.0 \\
$(15 \%)$ & $(19 \%)$ & $(12 \%)$ & & & & & & & \\
\hline
\end{tabular}

Values in parentheses indicate COV

Property values are in $\mathrm{N} / \mathrm{mm}^{2}$, with the exeption of in $\mathrm{kg} / \mathrm{m}^{3}$

${ }^{1}$ Experimental values from control samples

${ }^{2}$ Derived values from eq. (3), (4), (5), (6), (7), (8) and (9)

\subsection{EXPERIMENTAL RESULTS OF FINGER-JOINT LAMELLAS}

Mean values of modulus of elasticity and bending strength recorded for each failure mode (i.e., 1, 2, and 3, as described in 2.2), were obtained from the three experimental samples: i) control lamellas without finger joints (hereinafter referred to as "controls"); ii) glued finger joints with EPI (herein after referred to as "fj-EPI"); and iii) glued finger joints with PUR (hereinafter referred to as "fj-PUR"). Table 3 shows mean properties and failure modes under bending tests for the three samples.

Table 3: Experimental bending results of the three samples (mean values)

\begin{tabular}{|c|c|c|c|c|}
\hline \multicolumn{2}{|c|}{ Sample } & i) Control & ii) fj-EPI & iii) fj-PUR \\
\hline \multicolumn{2}{|c|}{ Specimens per sample (n) } & 20 & 40 & 20 \\
\hline \multicolumn{2}{|c|}{ Moisture content (\%) } & $\begin{array}{c}11.02 \\
( \pm 4 \%)\end{array}$ & $\begin{array}{c}9.12 \\
( \pm 3 \%)\end{array}$ & $\begin{array}{c}9.09 \\
( \pm 3 \%)\end{array}$ \\
\hline \multicolumn{2}{|c|}{$E_{0, \text { mean }}\left(\mathbf{N} / \mathbf{m m}^{2}\right)$} & $\begin{array}{c}15363^{\mathrm{a}} \\
( \pm 15 \%)\end{array}$ & $\begin{array}{l}12394^{\mathrm{b}} \\
( \pm 19 \%)\end{array}$ & $\begin{array}{l}13326^{\mathrm{b}} \\
( \pm 22 \%)\end{array}$ \\
\hline Failure mode 1 (wood) & $\mathbf{E}_{0, \text { mean_1 }}$ & $\begin{array}{l}15363^{\mathrm{a}} \\
( \pm 15 \%)\end{array}$ & $\begin{array}{l}10786^{\mathrm{b}} \\
( \pm 20 \%)\end{array}$ & $\begin{array}{l}11619^{b} \\
( \pm 15 \%)\end{array}$ \\
\hline Failure mode 2 (mixed) & $\mathbf{E}_{0, \text { mean_2 }}$ & -- & $\begin{array}{l}12784^{\mathrm{a}} \\
( \pm 20 \%)\end{array}$ & $\begin{array}{l}12332^{\mathrm{a}} \\
( \pm 21 \%)\end{array}$ \\
\hline $\begin{array}{c}\text { Failure mode } 3 \\
\text { (adhesive) }\end{array}$ & $\mathbf{E}_{0, \text { mean_3 }}$ & -- & $\begin{array}{r}13483^{a} \\
( \pm 13 \%)\end{array}$ & $\begin{array}{l}15525^{\mathrm{b}} \\
( \pm 17 \%)\end{array}$ \\
\hline \multicolumn{2}{|c|}{$\mathbf{f}_{\mathrm{m}}\left(\mathrm{N} / \mathbf{m m}^{2}\right)$} & $\begin{array}{c}91.88^{\mathrm{a}} \\
( \pm 19 \%)\end{array}$ & $\begin{array}{c}59.96^{\mathrm{a}} \\
( \pm 15 \%)\end{array}$ & $\begin{array}{c}72.13^{\mathrm{b}} \\
( \pm 14 \%)\end{array}$ \\
\hline Failure mode 1 (wood) & $\mathbf{f}_{\mathbf{m}_{-} 1}$ & $\begin{array}{c}91.88^{a} \\
( \pm 19 \%)\end{array}$ & $\begin{array}{c}56.47^{\mathrm{b}} \\
( \pm 14 \%)\end{array}$ & $\begin{array}{l}60.88^{b} \\
( \pm 5 \%)\end{array}$ \\
\hline
\end{tabular}


Experimental and numerical evaluation of the structural performance of Uruguayan Eucalyptus grandis finger-joint

\begin{tabular}{|c|c|c|c|c|}
\hline Failure mode 2 (mixed) & $\mathbf{f}_{\mathrm{m}_{-} 2}$ & -- & $\begin{array}{c}58.51^{\mathrm{a}} \\
( \pm 13 \%)\end{array}$ & $\begin{array}{l}69.48^{\mathrm{b}} \\
( \pm 9 \%)\end{array}$ \\
\hline $\begin{array}{c}\text { Failure mode } 3 \\
\text { (adhesive) }\end{array}$ & $\mathbf{f}_{\mathrm{m}_{-} 3}$ & -- & $\begin{array}{c}65.38^{a} \\
( \pm 13 \%) \\
\end{array}$ & $\begin{array}{c}79.18^{\mathrm{b}} \\
( \pm 11 \%) \\
\end{array}$ \\
\hline \multicolumn{5}{|c|}{ Failure mode percentage } \\
\hline Failure mode 1 (wood) & & $100 \%$ & $30 \%$ & $20 \%$ \\
\hline Failure mode 2 (mixed) & & & $40 \%$ & $35 \%$ \\
\hline Failure mode 3 (adhesive) & & & $30 \%$ & $45 \%$ \\
\hline
\end{tabular}

Within fj-EPI, specimens showed similar percentages of failure for the three modes; within fj-PUR, percentage of failure in mode 1 was inferior to those corresponding to modes 2 and 3 . In both samples, low percentages ( $30 \%$ in fjEPI and $20 \%$ in fj-PUR) of failure in mode 1 (i.e., $100 \%$ wood) were observed.

Controls presented a significantly higher mean value of modulus of elasticity compared to those of fj-EPI and fjPUR, being these last two, similar to each other. Focusing on the failure mode, significant differences between fj-EPI and fj-PUR were observed, but just for specimens that failed by adhesive (mode 3). Note that the modulus of elasticity, evaluated in the elastic phase of the load-deflection curve it is not affected by the ultimate load, which in modes 1 and 2, occurs once the elastic-plastic phase has been reached in the compressed area of the specimen. However, failure by adhesive (mode 3 ) can occurs in the elastic phase, affecting the modulus of elasticity depending on the adhesive type.

Typical load-deflection curves for lamellas glued with EPI or glued with PUR, against controls (i.e., without finger joint) are depicted in Figure 4.

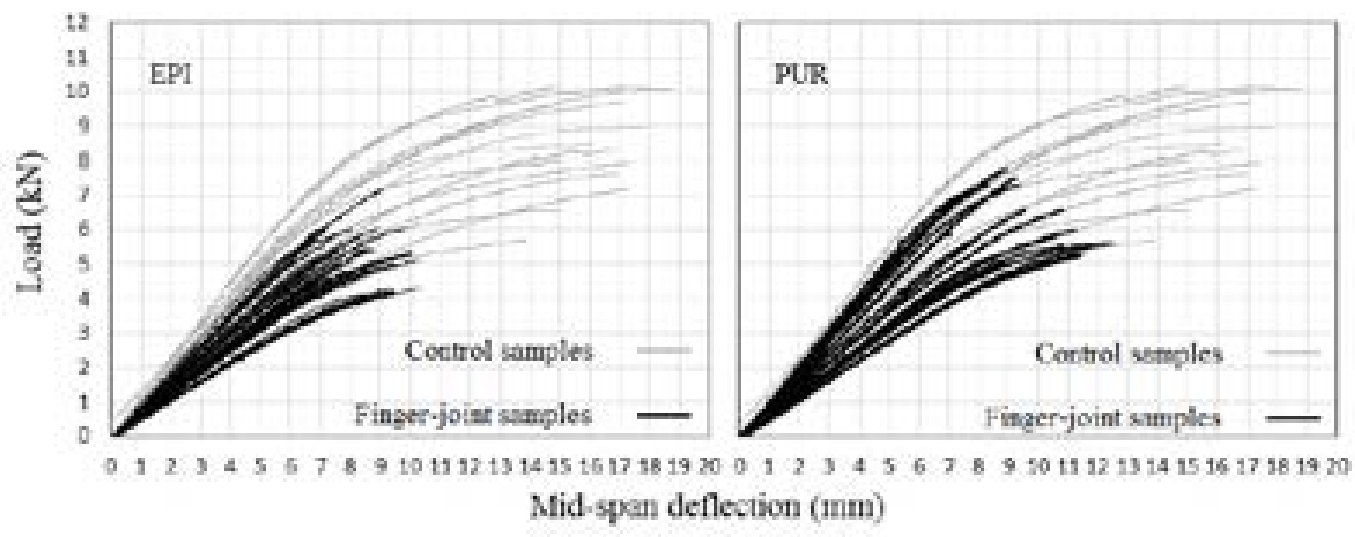

Figure 4: Load-mid-span deflection curves of finger-jointed samples with EPI (left) and PUR (right) adhesive compared to control samples curves (grey color)

As can be observed, the peak load attained in finger-jointed lamellas was lower than in controls. While failure of controls occurred in the elasto-plastic phase, failure of finger-jointed appeared close to the yield limit, shown in Figure 4 as the inflection point of the curves. Bending strength were significantly higher in fj-PUR $\left(f_{m}=72.13 \mathrm{~N} / \mathrm{mm}^{2}\right)$ compared to those observed in fj-EPI $\left(f_{m}=59.96 \mathrm{~N} / \mathrm{mm}^{2}\right)$, being both, lower than controls $\left(f_{m}=91.88 \mathrm{~N} / \mathrm{mm}^{2}\right)$. These findings were higher than those presented by Piter et al. (Piter et al. 2007b) for finger joint lamellas of Argentinean $E$. grandis glued with melamine-urea-formaldehyde adhesive $\left(f_{m}\right.$ between 46.9 and $\left.49.7 \mathrm{~N} / \mathrm{mm}^{2}\right)$.

Boxplots of bending properties by failure mode for controls and finger-jointed samples are shown in Figure 5 . 

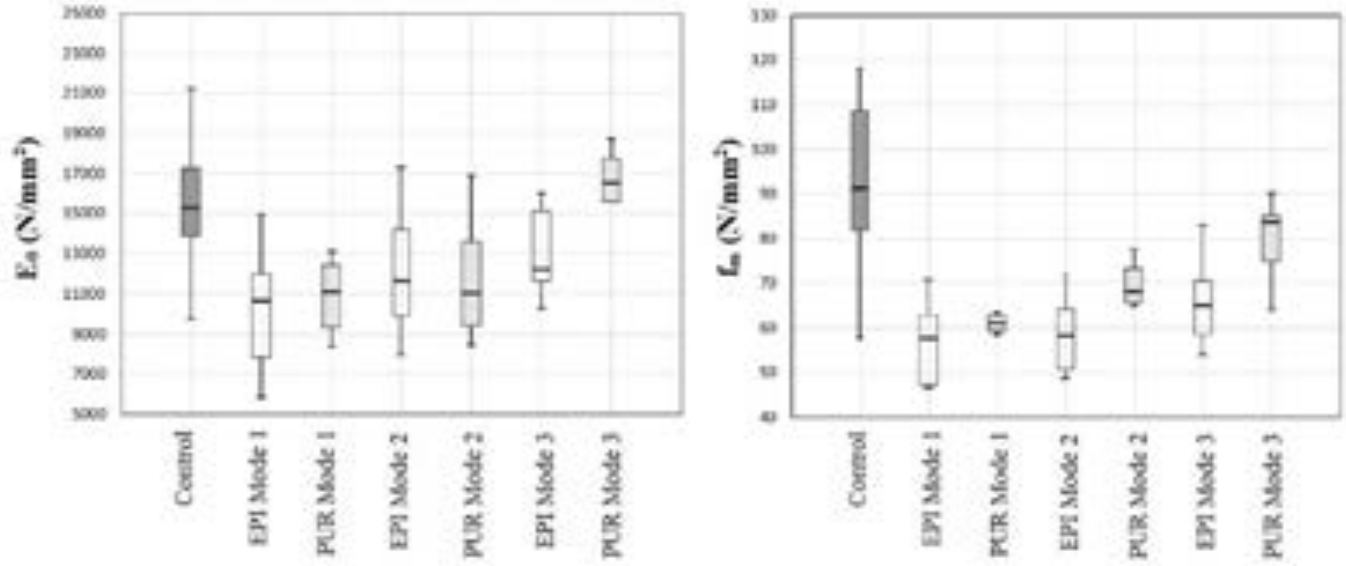

Figure 5: Modulus of elasticity and bending strength by adhesive type and failure mode

Analysis of $\mathrm{E}_{0 \text {,mean }}$ by failure mode within each fj-EPI and fj-PUR samples, reveals an increasing trend of mean values from mode 1 to mode 3 (Figure 5).

Similarly, bending strength in regard to failure mode within each fj-EPI and fj-PUR samples, shows an increase in $f_{m}$ from failure mode 1 to failure mode 3 . The lowest bending strengths observed in specimens that failed $100 \%$ by wood (mode 1) could mislead interpretations by contradicting the premise that the finger joint is a weak point. However, this behavior could be attributed to wood heterogeneity, masking its influence on the bending strength and showing failure modes by adhesive.

Comparison of strength values between fj-EPI and fj-PUR, for failure mode $1\left(56.47\right.$ and $60.88 \mathrm{~N} / \mathrm{mm}^{2}$, respectively), showed no significant differences, agreeing with the fact that the limiting factor was the wood strength rather than the glue line. On the other hand, significant superior values of $f_{m}$ in fj-PUR compared to fj-EPI for failure modes 2 and 3 were observed.

\subsection{VALIDATION OF FE MODEL}

Typical load-deflection curves comparing the experimental results and the numerical predictions for control samples are presented in Figure 6.

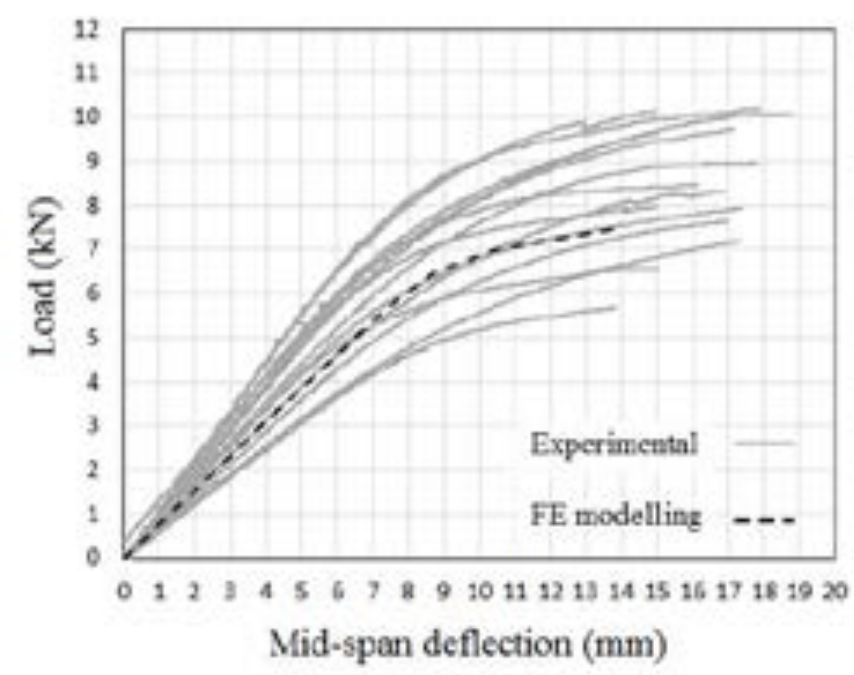

Figure 6: Load-mid-span deflection curves for experimental and numerical control samples 
As can be seen, the load-deflection curve obtained from the FE simulation matches the experimental curves. The numerical modulus of elasticity in the elastic phase resulted in $13442 \mathrm{~N} / \mathrm{mm}^{2}, 12.5 \%$ lower than the experimental mean value, yet in between the minimum-maximum experimental range.

In addition, two numerical models to simulate the experimental behavior of finger-jointed lamellas, one glued with EPI (fj-EPI), and one glued with PUR (fj-PUR), under bending tests were developed. Figure 7 presents the loaddeflection curves obtained from the models in comparison with the experimentals.

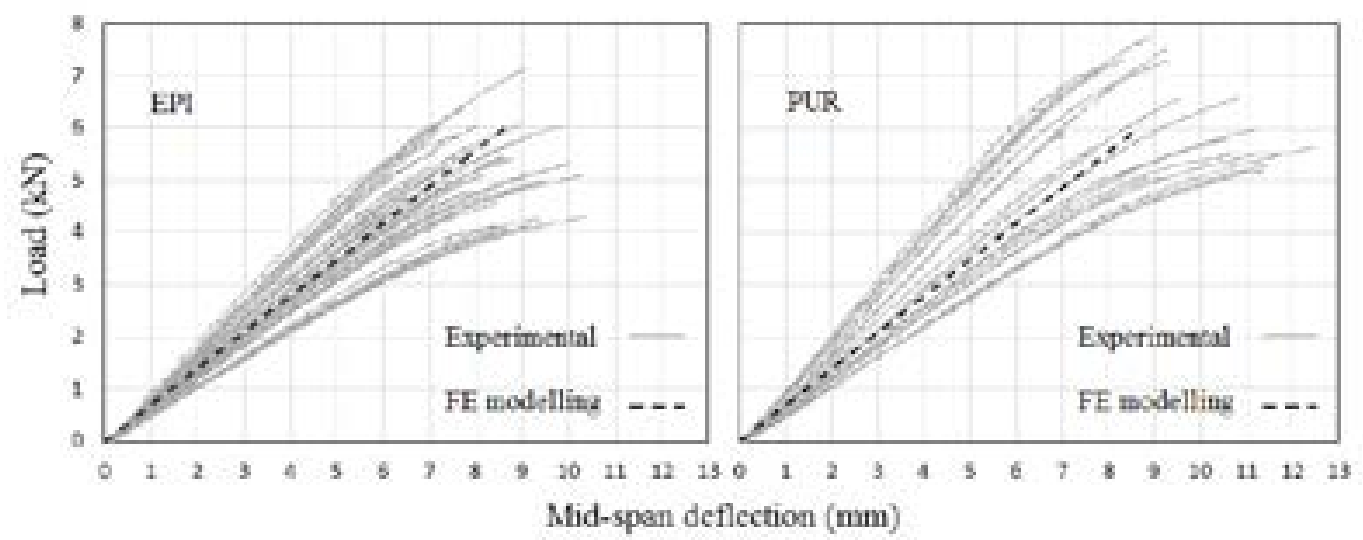

Figure 7: Load-mid-span deflection curves of experimental samples vs. FE models

The different adhesive (EPI and PUR) properties considered in the model had no significant influence on the numerical deflections and therefore, neither on the numerical modulus of elasticity. The adjustment of the numerical models was in good agreement with the experimental data. Table 4 shows the relative differences between the modulus of elasticity obtained from the numerical models and the mean values from experimental tests. A maximum error of $7.5 \%$ was observed for fj-PUR sample.

Table 4: Modulus of elasticity (E0) of finger-jointed lamellas obtained from numerical modeling and experimental testing

\begin{tabular}{c|c|c|c|c}
\hline & FE model & fj-EPI $^{\mathbf{1}}$ & fj-PUR $^{\mathbf{1}}$ & [fj-EPI+fj-PUR] $^{\mathbf{1}}$ \\
\hline$E_{0}\left(\right.$ mean value, N/mm $\left.{ }^{2}\right)$ & 12321 & 12394 & 13326 & 12805 \\
Error $(\%)$ & --- & 0.59 & 7.54 & 3.78 \\
\hline
\end{tabular}

${ }^{1}$ values obtained in experimental testing

Once the model was validated for stiffness prediction, the next step involved applying the model to predict the bending strength of finger-jointed lamellas. In doing so, based on the experimental results and considering an ideal behavior with proper adhesion of the finger-joints, two assumptions were alleged: i) the glue line is stronger than the wood leading to a $100 \%$-wood failure (mode 1); and ii) the 5 th percentile (characteristic value that reflect material variability) is similar for the whole sample, even in a hypothetical scenario in which every finger-joint fails by mode 1 (leading to an increase of the $f m$ mean value).

Bearing in mind that failure of lamellas under bending typically occurs in the tensile side, the bending strength was estimated by evaluation of the tensile stress distributions of wood, in the vicinity of the finger-joints. The predicted strengths were compared with experimental results of specimens that failed in mode 1 .

Figure 8 shows the distribution of tensile stresses, parallel and perpendicular to the grain, in the proximities of the finger joints, obtained from the numerical models. The maximum stresses were observed close to the bottom of the fingers, coinciding with the rupture zone of the experimental specimens. 


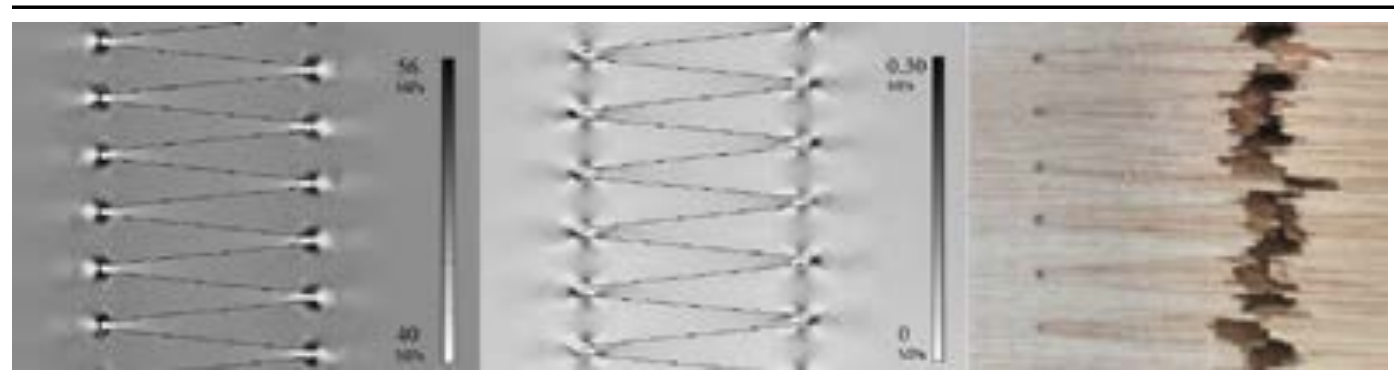

Figure 8: Stress distributions $\left(\mathrm{N} / \mathrm{mm}^{2}\right.$ ) parallel (left) and perpendicular (center) to the grain from FE modeling, and experimental

failure (right) under bending load

As expected, the tensile strength was higher in the direction parallel- than perpendicular- to the grain and therefore, the finger-joints failure occurred when the longitudinal tension stress at the bottom of the finger exceeded the estimated strength in tension parallel to the grain $\left(f_{t, 0}=55.13 \mathrm{~N} / \mathrm{mm}^{2}\right)$ of Eucalyptus grandis (see section 3.1). The peak load was determined for the first node that reached the value of $f_{t, 0}$, and the numerical bending strength was calculated by equation 2 . Table 5 shows the error in the prediction of the bending strength by FEM in comparison with the experimental values.

Table 5: Bending strength $\left(\mathrm{f}_{\mathrm{m}}\right)$ of finger-jointed lamellas obtained from numerical modelling and experimental testing

\begin{tabular}{c|c|c|c|c|c|c}
\hline & FE model & fj-EPI & fj-PUR & $\begin{array}{c}\text { [fj-EPI+fj- } \\
\text { PUR] }\end{array}$ & \multicolumn{2}{|c}{ [fj-EPI+fj-PUR] } \\
\hline$f_{m}$ (mean value, N/mm $\left.{ }^{2}\right)$ & 50.26 & 56.47 & 60.88 & 56.48 & $f_{05}\left(5^{\text {th }}\right.$ percentile $)$ & 47.29 \\
Error $(\%)$ & --- & 10.99 & 17.44 & 11.01 & & 6.28 \\
\hline
\end{tabular}

The numerical bending strength showed 11 to $17 \%$ lower values than the experimental means. Comparing the numerical results with the $5^{\text {th }}$ percentile of experimental $f_{m}$, the estimation error is reduced to $6 \%$. This decrease could be attributed to the way in which $f_{t, 0}$ was calculated, i.e., by the equation specified in EN 338 (CEN 2016b), which, due to safety reasons is conservative oriented, instead of using experimental data. Nevertheless, it is worth noting that employing the mechanical properties derived by EN 338 (CEN 2016b) equations leads to a reasonably prediction of the bending strength from Eucalyptus grandis finger-joints.

Since the finger geometry has a relevant effect on the performance of the structural joints (Bustos et al. 2003; Tran et al. 2015), several finger-joint geometries were considered in FE modeling. The strength performance of the different geometries were evaluated just for mode 1 , where failure occurs due to tension stresses in wood, rather than to adhesive (failure modes 2 and 3 ) where the modeling of the wood-adhesive interaction becomes umpredictable. Table 6 shows the finger-joint geometries evaluated:

Table 6: Finger joint geometries evaluated by FEM

\begin{tabular}{c|c|c|c}
\hline Finger code & Finger length $\boldsymbol{l}(\mathbf{m m})$ & Pitch $\boldsymbol{p}(\mathbf{m m})$ & Tip thickness $\boldsymbol{b}_{\boldsymbol{t}}(\mathbf{m m})$ \\
$10 / 4 / 0.5$ & 10 & 4.0 & 0.5 \\
$11 / 4 / 0.5$ & 11 & 4.0 & 0.5 \\
$13 / 4 / 0.5$ & 13 & 4.0 & 0.5 \\
$15 / 4 . / 0.5$ & 15 & 4.0 & 0.5 \\
$20 / 5 / 0.5$ & 20 & 5.0 & 0.5 \\
$20 / 6 / 1.0$ & 20 & 6.2 & 1.0 \\
$30 / 6 / 1.0$ & 30 & 6.2 & 1.0 \\
\hline
\end{tabular}

Finger lengths of 15, 20 and $30 \mathrm{~mm}$ (with their corresponding values of pitch and tip thickness) indicated in EN 14081 and, lengths of 10,11 and $13 \mathrm{~mm}$, usually employed in Uruguayan industries, were considered. The modeling parameters were similar to those defined in 2.3. The estimated bending strength obtained for each finger-joint geometry is shown in Figure 9: 
Experimental and numerical evaluation of the structural performance of Uruguayan Eucalyptus grandis finger-joint

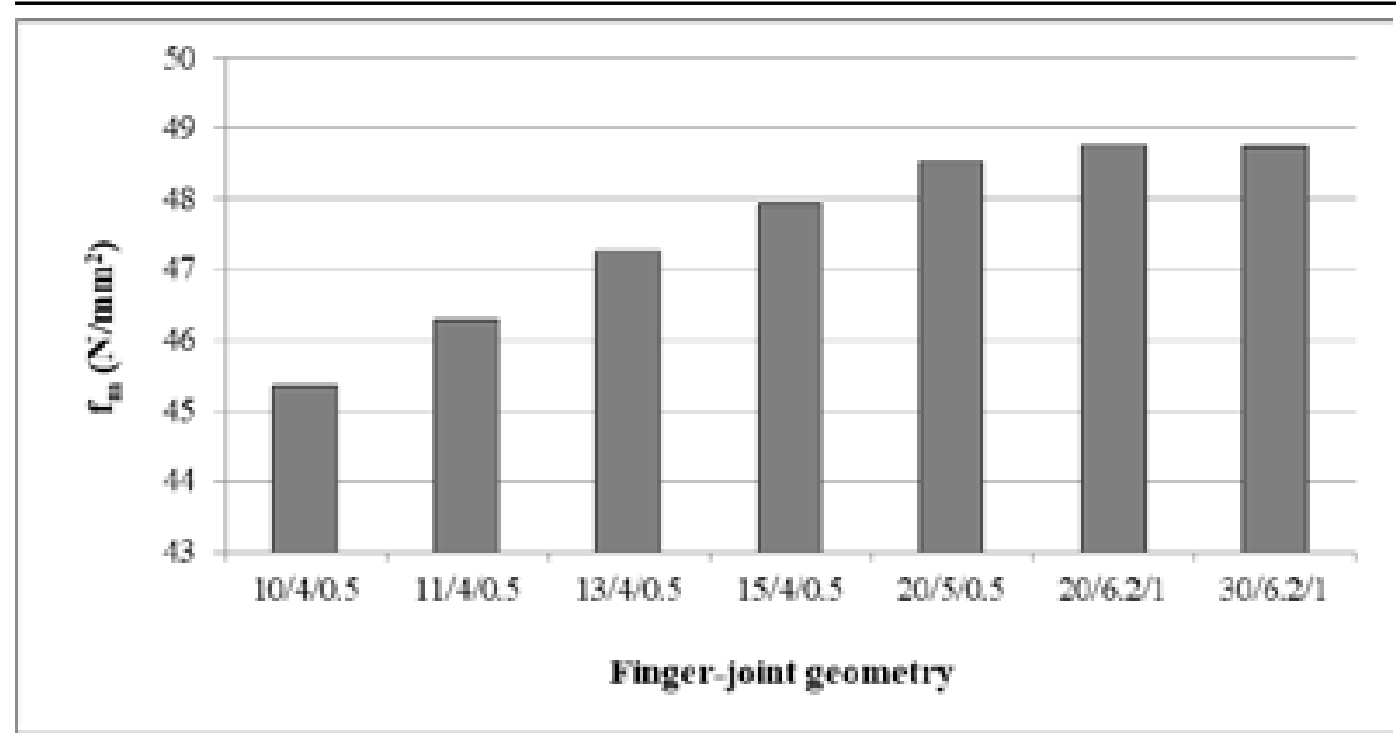

Figure 9: Bending strength $\mathrm{f}_{\mathrm{m}}\left(\mathrm{N} / \mathrm{mm}^{2}\right)$ of different finger-joint geometry estimated by FEM

As can be seen, the numerical bending strength slightly improved by increasing the finger length, results that compare relatively well with those obtained from tests for fingers with codes 10/4/0.5, 11/4/05 and 13/4/05. As was previously mentioned, the improvement in strength is related to the different distribution of tensile stresses near the bottom of the finger, being valid just for failure mode 1. Increasing the length of the finger entails an augmentation of the contact area between wood and adhesive, which in turn should improve modes 2 and 3 results. Results showed that lower bending strength values (and therefore defining the characteristic values) were obtained in samples with failure mode 1. Under this premise, the evaluation of different geometries by FEM indicates that a finger length of 20 $\mathrm{mm}$ is optimal for maximizing the bending strength for failure mode 1 .

\section{CONCLusions}

Eucalyptus grandis finger-joints glued with different adhesives (PUR and EPI) were tested in bending to obtain their mechanical properties and to evaluate the failure mode. Additionally, numerical simulations were developed to model the finger-joints and to estimate their strength and stiffness.

The experimental tests showed not significant differences in the modulus of elasticity $\left(\mathrm{E}_{0}\right)$ for lamellas with fingerjoints glued with EPI and with PUR, being both significantly lower than those from controls (lamellas without fingerjoint). However, the bending strength $\left(\mathrm{f}_{\mathrm{m}}\right)$ of finger-joints was significantly higher for PUR than for EPI, being both lower than controls. The lowest bending properties obtained in samples with failure mode 1 (failure $100 \%$ by wood) suggests that the characteristic strength value of finger joints defined by the wood and not by the adhesive.

Despite the relative high values of bending strength reached in the finger-joints, high percentages of undesirable failure type, i.e., in the glue line (modes 2 and 3) for both adhesives (70\% in EPI samples and $80 \%$ in PUR samples), were found. This observation suggests that the wood-adhesive interphase has yet to be improved, probably by optimizing the manufacturing parameters or evaluating the performance of new adhesives.

There were no differences on the numerical results for the modeling of the lamellas in function of the type of adhesives used for the gluing of the finger joints. The numerical modulus of elasticity of finger-joint lamellas was estimated by with a maximum error of $7.54 \%$ with respect to the experimental mean values. From these models, bending strength could be predicted in a conservative way, with an error of $6.28 \%$ compared with the experimental value of the $5^{\text {th }}$ percentile.

FEM modeling showed that optimum finger geometry is $20 \mathrm{~mm}$ length, with a gap of $6.2 \mathrm{~mm}$ and tip thickness of $1 \mathrm{~mm}$. This finger configuration maximizes the bending strength in failure modes 1 and, therefore, the characteristic value.

In further works, the accuracy of the numerical models for bending strength prediction could be improved by using experimental data as input values for the entire set of elastic and mechanical properties needed. In addition, more 
complex FE models considering the interaction between wood and adhesive for modeling failure modes 2 and 3 , should be developed.

\section{REFERENCES}

Ahmad Z, Lum WC, Lee SH, Razlan MA, Mohamad, WHW (2017) Mechanical properties of finger jointed beams fabricated from eight Malaysian hardwood species. Constr Build Mater 145:464-473. doi: 10.1016/j.conbuildmat.2017.04.016

Ayarkwa J, Hirashima Y, Sasaki Y (2000) Effect of finger geometry and end pressure on the flexural properties of finger-jointed tropical African hardwoods. For Prod J 50:53

Ayarkwa J, Hirashima Y, Sasaki Y Ando K (2000) Effect of glue type on flexural and tensile properties of finger-jointed tropical African hardwoods. For Prod J 50:59

Bourreau D, Aimene Y, Beauchene J, Thibaut, B (2013) Feasibility of glued laminated timber beams with tropical hardwoods. Eur $J$ Wood Wood Prod 75:653-662

Bourscheid CB, Terezo RF, Stüpp AM, Vanzella DA (2015) Desempenho mecânico de madeira laminada colada de Eucalyptus spp. In: Anais do I I Congresso Brasileiro de Ciencia e Tecnologia da Madeira - CBCTEM. Belo Horizonte, Brazil

Bustos C, Mohammad M, Hernández RE, Beauregard R (2003) Effects of curing time and end pressure on the tensile strength of finger-jointed black spruce lumber. For Prod J 53:85

Calil Neto C, Christoforo AL, Ribeiro Filho SM, Moni S., Rocco Lahr F.A., Calil Junior C (2014) Evaluation of strength to shear and delamination in glued laminated wood. Ciência Florest 23:989-996

Camú CT, Aicher S (2018) A stochastic finite element model for glulam beams of hardwoods. In: World Conference on Timber Engineering. Seoul, South Korea

CEN (2013) EN 14080. Timber structures. Glued laminated timber and glued solid timber. Requirements

CEN (2015) EN 16351. Timber structures. Cross laminated timber. Requirements

CEN (2010) EN 408. Timber structures. Structural timber and glued laminated timber. Determination of some physical and mechanical properties.

CEN (2016a) EN 384. Structural timber. Determination of characteristic values of mechanical properties and density

CEN (2016b) EN 338. Structural timber. Strength classes

de Castro San Román J (2005) Experiments on Epoxy, Polyurethane and ADP Adhesives: Composite construction laboratory, Technical Report Nr. CCLab2000.1b/1

Dieste A (2012) Program to promote exports of wood products [Programa de promoción de exportación de productos de madera]. Technical Report 1. Dirección Nacional de Industrias. Ministerio de Industrias, Energía y Minería. Consejo Sectorial Forestal-Madera. Montevideo, Uruguay. pp 35

Franke B, Schusser A, Müller A (2014) Analysis of finger joints from beech wood. In: World Conference on Timber Engineering. Quebec, Canada

Franke S, Marto J (2014) Investigation of Eucalyptus globulus wood for the use as engineered wood material. In: Proceedings of the World Conference on Timber Engineering. Quebec, Canada

IRAM 9662-2 (2015) Structural glued laminated timber. Visual grading of boards by strength. Part 2. Boards of Eucalyptus grandis [Madera laminada encolada estructural. Clasificación visual de las tablas por resistencia. Parte 2. Tablas de Eucalyptus grandis]

Iwakiri S, Monteiro Matos JL, Prata JG, Trianoski R, Parchen CF, Gomes Castro V, Teixeira Iwakiri V (2014) Characteristics of glued laminated beams made of teak wood (Tectona grandis). Floresta e Ambient 21:269-275

Khelifa M, Auchet S, Méausoone PJ, Celzard A (2015) Finite element analysis of flexural strenghening of timber beams with Carbon Fibre-Reinforced Polymers. Eng Struct 101:364-375

Konnerth J, Gindl W, Müller U (2007) Elastic properties of adhesive polymers. I. Polymer films by means of electronic speckle pattern interferometry. J Appl Polym Sci 103:3936-3939. doi: 10.1002/app.24434

Lara-Bocanegra AJ, Majano-Majano A, Crespo J, Guaita M (2017) Finger-jointed Eucalyptus globulus with 1C-PUR adhesive for high performance engineered laminated products. Constr Build Mater. doi: 10.1016/j.conbuildmat.2017.01.004

Millner HR, Yeoh E (1991) Finite element analysis of glued timber finger joints. J Struct Eng 117(3):755-766

Moya L, Pérez-Gomar C, Vega A, et al (2019) RELATIONSHIP BETWEEN MANUFACTURING PARAMETERS AND STRUCTURAL PROPERTIES OF EUCALYPTUS GRANDIS GLUED LAMINATED TIMBER. Maderas Cienc y Tecnol 21:21

Özçifçi A, Yapici $F$ (2008) Structural performance of the finger-jointed strength of some wood species with different joint configurations. Constr Build Mater 22(7):1543-1550 
Experimental and numerical evaluation of the structural performance of Uruguayan Eucalyptus grandis finger-joint

Pereira MC, Calil Neto C, Icimoto FH, Calil Junior C (2016) Evaluation of tensile strength of a Eucalyptus grandis and Eucalyptus urophyla Hibrid in wood beams bonded together by means of finger joints and polyurethane-based glue. Mater Res 19:12701275

Piter JC, Cotrina AD, Sosa Zitto MA, Stefani PM, Torrán EA (2007) Determination of characteristic strength and stiffness values in glued laminated beams of Argentinean Eucalyptus grandis according to European standards. Holz als Roh - und Werkst 65:261-266. doi: 10.1007/s00107-006-0161-5

Raknes E (1980) The influence of production conditions on the strength of finger-joints (of sawnwood in Norway). In: Transmitted by the Government of Norway in FAO, Geneva (Switzerland). Joint ECE/FAO Agriculture and Timber Div. Seminar on the PRoduction, Marketing and Use of Figer-Jointed Sawnwood. Hamar (Norway)

Sebera V, Muszyński L, Tippner J, Noyel M, Pisaneschi T, Sundberg B (2015) FE analysis of CLT panel subjected to torsion and verified by DIC. Mater Struct 48(1-2):451-459. doi: 10.1617/s11527-013-0195-1

Serrano E, Gustafsson J, Larsen HJ (2001) Modeling of finger-joint failure in glued-laminated timber beams. J Struct Eng 127(8):914-921

Smardzewski J (1996) Distribution of stresses in finger joints. Wood Sci Technol 30(6):477-489

Stoeckel F, Konnerth J, Gindl-altmutter W (2013) Mechanical properties of adhesives for bonding wood - A review. Int J Adhes Adhes 45:32-41

Tran VD, Oudjene M, Méausoone PJ (2015) Experimental and numerical analysis of the structural response of adhesively reconstituted beech timber beams. Compos Struct 119:206-217

Tran VD, Oudjene M, Méausoone PJ (2014) FE analysis and geometrical optimization of timber beech finger-joint under bending test. Int J Adhes Adhes 52:40-47. doi: 10.1016/j.ijadhadh.2014.03.007

Vassiliou V, Barboutis I, Karasterogiou S (2006) Effect of PVA bonding on finger-joint strength of steamed and unsteamed beech wood (Fagus sylvatica). J Appl Polym Sci 103:1664-1669

Volkmer T, Franke B, Schusser A (2014) Analysis of the penetration of adhesives at finger-joints in beech wood. In: In World Conference on Timber Engineering-WCTE. Quebec, Canada

Vrazel M, Sellers Jr T (2004) The effects of species, adhesive type and cure temperature on the strength and durability of a structural finger-joint. For Prod J 54:66 